\title{
Ceric ammonium nitrate impregnated on silica gel in the removal of the tert-butoxycarbonyl group
}

\author{
Jih Ru Hwu, ${ }^{*},{ }^{b}$ Moti L. Jain, $,{ }^{a},{ }^{b}$ Fu-Yuan Tsai, ${ }^{a}, b$ A. Balakumar, ${ }^{b}$ \\ G. H. Hakimelahi, ${ }^{b}$ and Shwu-Chen Tsay ${ }^{c}$ \\ ${ }^{a}$ Organosilicon and Synthesis Laboratory, Department of Chemistry, \\ National Tsing Hua University, Hsinchu, Taiwan 300, ${ }^{b}$ Institute of Chemistry, \\ Academia Sinica, Nankang, Taipei, Taiwan 115, and \\ ${ }^{c}$ Well-being Biochemical Corporation, Neihu Chiu, Taipei, \\ Taiwan 114, Republic of China \\ E-mail: jrhwu@mx.nthu.edu.tw
}

\section{Dedicated to Professor James R. Bull for his contributions to Chemistry and on his retirement from the University of Cape Town}

\begin{abstract}
The tert-butoxycarbonyl group was efficiently (80-99\% yields) removed from an amino, hydroxy, or mercapto functionality in organic compounds by use of 0.20 equiv of $\mathrm{Ce}\left(\mathrm{NH}_{4}\right)_{2}\left(\mathrm{NO}_{3}\right)_{6}$ in acetonitrile at reflux. Application of the solid-supported reagent involving the use of 0.20 equiv of $\mathrm{Ce}\left(\mathrm{NH}_{4}\right)_{2}\left(\mathrm{NO}_{3}\right)_{6}$ impregnated on silica gel in toluene at reflux gave the deprotected products in 90-99\% yields. These reactions likely proceed through an electron transfer process.
\end{abstract}

Keywords: Ceric ammonium nitrate, silica gel, tert-butoxycarbonyl, deprotection, amino ester

\section{Introduction}

The tert-butoxycabonyl ( $t$-BOC) group is often used for the protection of amino acids in peptide synthesis. ${ }^{1}$ Reagents used to cleave the $t$-BOC group include boron trifluoride, ${ }^{2}$ hydrogen chloride, ${ }^{3}$ hydrogen fluoride, ${ }^{4}$ sulfuric acid, ${ }^{5}$ trifluoroacetic acid, ${ }^{6}$ trimethylsilyl triflate, $^{7-9}$ trimethylsilyl perchlorate, ${ }^{8}$ etc. Each of these methods, however, has its own limitations. ${ }^{1-9}$ Therefore it is desirable to develop a new and efficient method for deprotection of the $t$-BOC group.

Ceric ammonium nitrate $\left(\mathrm{Ce}\left(\mathrm{NH}_{4}\right)_{2}\left(\mathrm{NO}_{3}\right)_{6}, \mathrm{CAN}\right)$ can function as a one-electron transfer catalyst in various organic reactions. ${ }^{10-12}$ Recently we have reported the use of a catalytic 
amount of CAN for removal of the triphenylmethyl (Tr), monomethoxytrityl (MMTr), and tertbutoxycabonyl (t-BOC) groups from organic compounds. ${ }^{11}$ Under the neutral conditions applied, several acid-sensitive groups survive, including isopropylidene, (dimethylamino)methylidene, tert-butyldimethylsilyl, and acyl functionalities. ${ }^{11}$ Furthermore, indole, pyrimidine, and phthalimide nuclei remain intact and the undesired racemization in amino esters does not occur. ${ }^{11}$

Use of CAN in acetonitrile at reflux or the CAN impregnated on silica gel in boiling $\mathrm{CH}_{2} \mathrm{Cl}_{2}$ did not allow us to remove the tert-butyl group from 1-(tert-butoxy)-2-methoxyethane. We considered that an electron-withdrawing group directly connected to the tert-butyl functionality (e.g., $\mathrm{RXCOO}(t-\mathrm{Bu}) ; \mathrm{X}=\mathrm{NR}, \mathrm{O}$, and $\mathrm{S}$ ) would increase the potential for it to become a carbocationic species. Thus we investigated the possibility of using CAN as a catalyst for efficient removal of the $t$-BOC group from amino esters and related compounds. Herein we report our findings from a systematic study that CAN alone or, especially, CAN adsorbed on silica gel functioned as an effective reagent for removal of the $t$-BOC functionality from a variety of organic substrates.

\section{Results and Discussion}

We treated several $t$-BOC-containing compounds (i.e., 1, 3, 5, 7, 9, 11, and 13) in acetonitrile with CAN (0.20 equiv) to give the deprotected products (i.e., 2, 4, 6, 8, 10, 12, and 14) in 8099\% yields (Scheme 1 and Table 1). Furthermore, we tested the efficiency of the CAN-silica gel reagent (containing 0.20 equiv of CAN) on debutylation. Thus treatment of this reagent with tertbutylbenzoate (15) in $\mathrm{CH}_{2} \mathrm{Cl}_{2}$ at reflux gave the corresponding benzoic acid (16) in $90 \%$ yield after $6.0 \mathrm{~h}$. The same reaction went to completion (95\% yield) in $\mathrm{CHCl}_{3}, \mathrm{CCl}_{4}$, or toluene at reflux after 6.5, 3.0, and $0.20 \mathrm{~h}$, individually. Debutylation, however, did not proceed in the above solvents in the absence of silica gel. This is due to low solubility of CAN in those solvents. Moreover, we found that the same deprotection reaction required much longer reaction time (e.g., 30-45 h) for completion at a lower temperature (e.g., $25^{\circ} \mathrm{C}$ ). Our results indicate the importance on the choice of solvents as well as the reaction temperature during application of the CAN-silica gel reagent in de-tert-butoxycarbonylation and debutylation reactions.

Adsorption of the $t$-BOC-containing compounds to silica gel impregnated with CAN could bring the substrates and the catalyst into proximity. ${ }^{13,14}$ This facilitates the electron transfer process between CAN and substrates; thus it may cause the deprotection reactions to proceed

much faster. ${ }^{15-17}$ Use of silica gel as support could also increase the effective surface area and constrain both the substrate and the reactant in pores for decreasing the entropy of activation for electron transfer. ${ }^{13,14}$

To realize generality of the CAN-silica gel reagent in de-tert-butoxycabonylation, we treated it with the $t$-BOC containing compounds $1,3,5,7,9,11$, and 13 in toluene at reflux. After $\sim 1.0$ $\min -3.0 \mathrm{~h}$, the deprotected products (i.e., 2, 4, 6, 8, 10, 12, and 14) were obtained in 90-99\% 
yields (see Table 1). Thus, this newly developed procedure was widely applicable to compounds bearing a $t$-BOC group attached to a nitrogen (i.e., 1, 3, 5, 7, and 9), an oxygen (i.e., 11), or a sulfur atom (i.e., 13). Moreover, the $t$-BOC group can be selectively cleaved in the presence of tert-butyl ether as shown in the conversion of $\mathbf{9}$ to $\mathbf{1 0}$ (93\% yield, Table 1). To the best of our knowledge, this is the first example of selective removal of the $t$-BOC group in the presence of a tert-butyl ether. ${ }^{9}$<smiles>COC(=O)[C@H](C)N</smiles>

1. $\mathrm{R}=\mathrm{COOBu}{ }^{t}$
2. $\mathrm{R}=\mathrm{H}$$\longleftarrow \begin{array}{r}\mathrm{I} \text { or } \mathrm{II} \\ (85-90 \%)\end{array}$<smiles>[R]N1CCC[C@H]1C(=O)OCc1ccccc1</smiles>
5. $\mathbf{R}=\mathbf{C O O B u}$
6. $\mathbf{R}=\mathbf{H}$

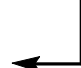
I or II
(93-95\%)<smiles></smiles>

9. $\mathrm{R}=\mathrm{COOBu}^{t}$

10. $R=H$

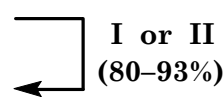<smiles>Cc1cc(C)nc([As])n1</smiles>

13. $\mathrm{R}=\mathrm{COOBu}{ }^{t}$

14. $R=H$<smiles>[R]N[C@H](Cc1ccccc1)C(=O)OCc1ccccc1</smiles>

3. $\mathrm{R}=\mathrm{COOBu}^{t}$

4. $R=H$ I or II $(90-95 \%)$<smiles>[R1]N[C@@H](Cc1c[nH]c2ccccc12)C(=O)OCP</smiles>

7. $\mathrm{R}=\mathrm{COOBu}^{t}$ I or II

8. $\mathbf{R}=\mathbf{H}$ (90-98\%)<smiles>[R]ON1C(=O)c2ccccc2C1=O</smiles>

11. $\mathrm{R}=\mathrm{COOBu}^{t}$

12. $R=H$

or II

(99\%)<smiles>CCOC(=O)c1ccccc1</smiles>
15. $\mathrm{R}=\mathrm{Bu}^{t}$
I or II
16. $R=H$ (95-98\%)

I. CAN (0.20 equiv), $\mathrm{MeCN}, \Delta$

II. CAN (0.20 equiv)-silica gel, toluene, $\Delta$

\section{Scheme 1}

This newly developed deprotection reaction could involve electron transfer processes. ${ }^{10-12,18}$ We propose a mechanism shown in Scheme 2 for removal of the $t$-BOC group from organic 
molecules 18 by using CAN-silica gel 17. Oxidation of the carbonyl group in 19, from adsorption of 18 to 17, by CAN would lead to the corresponding radical cations as shown in 20. Radical cations then undergo fragmentation to afford a tert-butyl cation and carboxylate radicals as shown in 21. Deprotonation of the tert-butyl cation gives isobutene. In situ, $\mathrm{Ce}^{\mathrm{IV}}$ is regenerated from $\mathrm{Ce}$ III during the reduction of carboxylate radicals in $\mathbf{2 1}$ to carboxylate ions in 22. ${ }^{18}$ Consequently, the extrusion of $\mathrm{CO}_{2}$ from carboxylate ions followed by protonation produces the free amines 23.

Table 1. Removal of the tert-butoxycarbonyl group from protected compounds by use of CAN ( 0.20 equiv) in MeCN or silica gel-supported CAN (0.20 equiv) in toluene at reflux

\begin{tabular}{cccccc}
\hline Starting & & \multicolumn{2}{c}{ Time $(\mathrm{h})$} & \multicolumn{2}{c}{ Yield (\%) by Isolation } \\
\hline Material & Product & CAN & CAN-SiO & CAN & CAN-SiO $_{2}$ \\
\hline 1 & 2 & 12 & 2.0 & 85 & 90 \\
3 & 4 & 10 & 1.5 & 95 & 90 \\
5 & 6 & 2.0 & 0.50 & 93 & 95 \\
7 & 8 & 8.0 & 1.0 & 90 & 98 \\
9 & 10 & 14 & 3.0 & 80 & 93 \\
11 & 12 & 1.0 & 0.20 & 99 & 99 \\
13 & 14 & 0.20 & 0.010 & 96 & 98 \\
15 & 16 & 5.0 & 0.20 & 98 & 95 \\
\hline
\end{tabular}

In order to support our proposed mechanism, we carried out the reactions of CAN-silica gel with 9, 11, and 13, individually, in the presence of 2,6-di-tert-butyl-4-methylphenol (0.050-0.45 equiv), which can function as a radical inhibitor. ${ }^{19}$ We found that de-tert-butoxycarbonylation did not proceed and the starting materials were recovered. On the other hand, in the absence of radical inhibitors but in the presence of $\mathrm{NaHCO}_{3}(0.45$ equiv), the above reactions still produced the desired compounds 10, 12, and 14, individually, in comparable yields. These results indicate that the reactions likely proceed through an electron transfer pathway rather than an acidcatalyzed cleavage.

\section{Conclusions}

Ceric ammonium nitrate adsorbed on silica gel functioned as an effective catalyst for removal of the $t$-BOC functionality from a variety of organic molecules. The undesired racemization in amino esters did not take place during cleavage of the $t$-BOC group under the applied conditions. Use of silica gel supported CAN allowed the deprotection reactions to proceed much faster and, often, to give the desired products in a higher yield. Advantages associated with this CAN-silica 
gel reagent include mild reaction conditions, a relatively short reaction time, and a small amount of the reagent required.

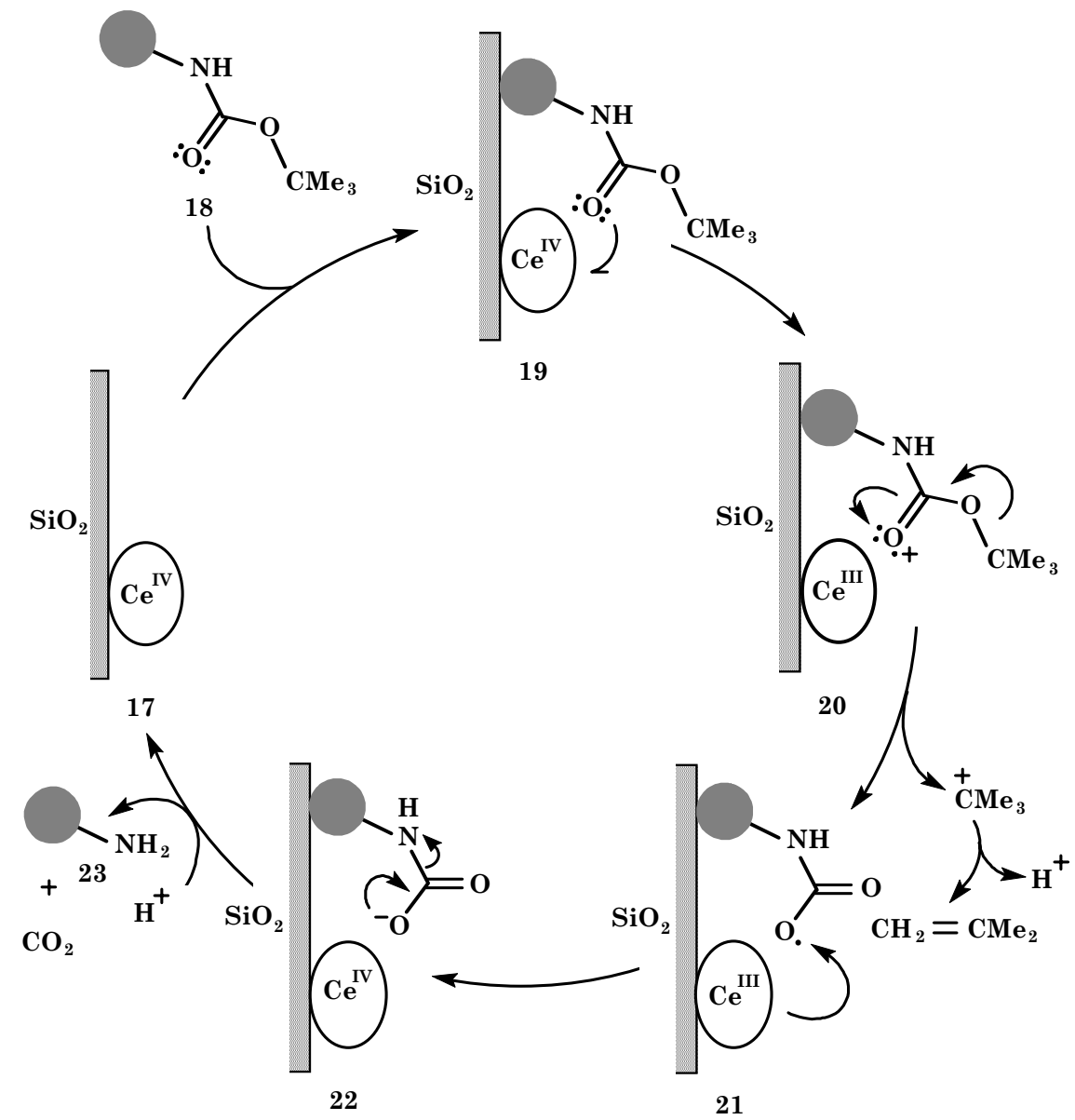

Scheme 2

\section{Experimental Section}

General Procedures. Reagents were purchased from Aldrich or Sigma Chemical Co. Dry ether was obtained by distillation from the sodium ketyl of benzophenone under nitrogen; ethyl acetate and hexanes were distilled over $\mathrm{CaH}_{2}$ under nitrogen. Melting points were obtained with a Büchi 510 melting point apparatus. Ultraviolet (UV) spectra were recorded on a Cary 118 spectrophotometer. Proton NMR spectra were obtained on a Varian XL-300 (300 MHz) spectrometer. Purification by gravity column chromatography was carried out by use of Merck reagent silica gel 60 (particle size 230-400 mesh). Thin-layer chromatography was carried out on glass plates $(20 \mathrm{~cm} \times 20 \mathrm{~cm})$ coated with a 1-mm thick layer of silica gel DSF-5 (Terrochem Laboratories). Analytical TLC was performed on precoated plates purchased from Merck (Silica 
Gel $60 \mathrm{~F}_{254}$ ). Compounds were visualized by use of $\mathrm{UV}$ light, $\mathrm{I}_{2}$ vapor, or $2.5 \%$ phosphomolybdic acid in ethanol with heating.

Preparation of silica gel-supported CAN. Neutral silica gel (8.02 g, Merck Kieselgel 60, particle size $0.063-0.200 \mathrm{~mm}, 70-230$ mesh) was mixed with a solution of CAN (2.01 g) in water $(2.0 \mathrm{~mL})$. Evaporation of water under reduced pressure $(0.10$ torr $)$ for $4.0 \mathrm{~h}$ gave a dry yellowish powder, which contained $20 \%$ (by weight) of CAN. This reagent stored in a wellcapped bottle was found active for at least six months.

Standard procedure for deprotection of the tert-BOC group by use of ceric ammonium nitrate. Method I. A solution of the tert-BOC protected compound (1.0 equiv) in MeCN was treated with a catalytic amount of CAN (0.20 equiv) and then was heated at reflux until the TLC did not show any starting material. The solvent was removed under reduced pressure and the residue was purified by column chromatography to afford the desired product with purity $>99.9 \%$, as checked by GC.

Method II. A solution of the tert-BOC protected compound (1.0 equiv) in toluene was treated with the CAN-silica gel reagent (containing 0.20 equiv of CAN) and then was heated at reflux until the TLC did not show any starting material. The solvent was removed under reduced pressure and the residue was purified by column chromatography to afford the desired product with purity $>99.9 \%$, as checked by GC.

(S)-(+)-Alanine methyl ester (2). Method I. The standard procedure was followed by use of (S)-(+)-N-(tert-butoxycarbonyl)alanine methyl ester (1, $325 \mathrm{mg}, 1.60 \mathrm{mmol}, 1.0$ equiv), CAN (175 mg, $0.319 \mathrm{mmol}, 0.20$ equiv), and $\mathrm{MeCN}$ (10 mL). After the reaction mixture was heated at reflux for $12 \mathrm{~h}$, it was worked up and the residue was purified by column chromatography (30\% EtOAc in hexanes as eluant) to afford 2 (140 mg, $1.36 \mathrm{mmol})$ in $85 \%$ yield; its hydrochloride salt: $\mathrm{mp} 109-110^{\circ} \mathrm{C}$; $[\alpha]^{25} \mathrm{D}+7.2^{\circ}$ (c 1.76, MeOH). Its physical properties and spectroscopic characteristics are consistent with those of an authentic sample. ${ }^{20}$

Method II. The standard procedure was followed by use of 1 (413 mg, 2.03 mmol, 1.0 equiv), the CAN-silica gel reagent (1.13 g, containing $222 \mathrm{mg}$ of CAN, $0.405 \mathrm{mmol}, 0.20$ equiv), and toluene $(7.0 \mathrm{~mL})$. After the reaction mixture was heated at reflux for $2.0 \mathrm{~h}$, it was worked up and the residue was purified by chromatography on silica gel (30\% EtOAc in hexanes as eluant) to afford 2 (189 mg, $1.83 \mathrm{mmol}$ ) in 90\% yield.

(S)-(-)-Phenylalanine benzyl ester (4). Method I. The standard procedure was followed by use of (S)-(-)- $N$-(tert-butoxycarbonyl)phenylalanine benzyl ester (3, $382 \mathrm{mg}, 1.07 \mathrm{mmol}, 1.0$ equiv), CAN (120 mg, $0.218 \mathrm{mmol}, 0.20$ equiv), and MeCN (10 mL). After the reaction mixture was heated at reflux for $10 \mathrm{~h}$, it was worked up and the residue was purified by column chromatography (EtOAc as eluant) to afford 4 (260 mg, $1.02 \mathrm{mmol}$ ) in 95\% yield; its $p$ toluenesulfonate salt: $\mathrm{mp} 169-171^{\circ} \mathrm{C} ;[\alpha]^{25} \mathrm{D}+7.0^{\circ}(c$ 1.90, MeOH). Its physical properties and spectroscopic characteristics are consistent with those of an authentic sample. ${ }^{20}$ 
Method II. The standard procedure was followed by use of 3 ( $290 \mathrm{mg}, 0.816 \mathrm{mmol}, 1.0$ equiv), the CAN-silica gel reagent (450 mg, containing $90.0 \mathrm{mg}$ of CAN, $0.164 \mathrm{mmol}, 0.20$ equiv), and toluene $(7.0 \mathrm{~mL})$. After the reaction mixture was heated at reflux for $1.5 \mathrm{~h}$, it was worked up and the residue was purified by column chromatography (30\% EtOAc in hexanes as eluant) to afford 4 (188 mg, $0.737 \mathrm{mmol}$ ) in $90 \%$ yield.

(S)-(-)-Proline benzyl ester (6). Method I. The standard procedure was followed by use of (S)(-)- $N$-(tert-butoxycarbonyl)proline benzyl ester (5, $456 \mathrm{mg}, 1.50 \mathrm{mmol}, 1.0$ equiv), CAN (165 mg, $0.300 \mathrm{mmol}, 0.20$ equiv), and $\mathrm{MeCN}$ (10 mL). After the reaction mixture was heated at reflux for $2.0 \mathrm{~h}$, it was worked up and the residue was purified by column chromatography (EtOAc as eluant) to afford 6 (285 mg, $1.39 \mathrm{mmol}$ ) in 93\% yield; its hydrochloride salt: mp 146$148{ }^{\circ} \mathrm{C} ;[\alpha]^{25} \mathrm{D}-50.1^{\circ}\left(c 1.37, \mathrm{H}_{2} \mathrm{O}\right)$. Its physical properties and spectroscopic characteristics are consistent with those of an authentic sample. ${ }^{20}$

Method II. The standard procedure was followed by use of 5 (337 mg, $1.10 \mathrm{mmol}, 1.0$ equiv), the CAN-silica gel reagent (610 mg, containing $122 \mathrm{mg}$ of CAN, $0.222 \mathrm{mmol}, 0.20$ equiv), and toluene $(7.0 \mathrm{~mL})$. After the reaction mixture was heated at reflux for $0.50 \mathrm{~h}$, it was worked up and the residue was purified by column chromatography (EtOAc as eluant) to afford 6 (215 mg, $1.05 \mathrm{mmol}$ ) in $95 \%$ yield.

(S)-(+)-Tryptophan benzyl ester (8). Method I. The standard procedure was followed by use of (S)-(+)-N-(tert-butoxycarbonyl)tryptophan benzyl ester (7, $527 \mathrm{mg}, 1.34 \mathrm{mmol}, 1.0$ equiv), CAN (148 $\mathrm{mg}, 0.270 \mathrm{mmol}, 0.20$ equiv) and $\mathrm{MeCN}(10 \mathrm{~mL})$. After the reaction mixture was heated at reflux for $8.0 \mathrm{~h}$, it was worked up and the residue was purified by column chromatography (5\% $\mathrm{MeOH}$ in EtOAc as eluant) to afford 8 (354 mg, $1.20 \mathrm{mmol}$ ) in 90\% yield; its hydrochloride salt: mp 220-222 ${ }^{\circ} \mathrm{C} ;[\alpha]^{25} \mathrm{D}+4.3^{\circ}$ (c 2.16, MeOH). Its physical properties and spectroscopic characteristics are consistent with those of an authentic sample. ${ }^{20}$

Method II. The standard procedure was followed by use of 7 ( $385 \mathrm{mg}, 0.977 \mathrm{mmol}, 1.0$ equiv), the CAN-silica gel reagent (540 mg, containing $108 \mathrm{mg}$ of CAN, $0.197 \mathrm{mmol}, 0.20$ equiv), and toluene $(7.0 \mathrm{~mL})$. After the reaction mixture was heated at reflux for $1.0 \mathrm{~h}$, it was worked up and the residue was purified by column chromatography ( $5 \% \mathrm{MeOH}$ in EtOAc as eluant) to afford 8 (281 mg, $0.955 \mathrm{mmol}$ ) in 98\% yield.

2-O-tert-Butoxyethylamine (10). Method I. The standard procedure was followed by use of $\mathrm{N}$ (tert-butoxycarbonyl)-2-O-tert-butoxyethylamine (9, $580 \mathrm{mg}, 2.67 \mathrm{mmol}, 1.0$ equiv), CAN (293 mg, $0.534 \mathrm{mmol}, 0.20$ equiv), and $\mathrm{MeCN}(10 \mathrm{~mL})$. After the reaction mixture was heated at reflux for $14 \mathrm{~h}$, it was worked up and the residue was purified by column chromatography (20\% $\mathrm{MeOH}$ in EtOAc as eluant) to afford $10(250 \mathrm{mg}, 2.14 \mathrm{mmol})$ in $80 \%$ yield: $R_{f}=0.61(50 \%$ $\mathrm{MeOH}$ in EtOAc); ${ }^{1} \mathrm{H}$ NMR (CD ${ }_{3} \mathrm{OD}$,) $\delta 1.13$ (s, $9 \mathrm{H}$ ), 2.89 (t, $J=8.0 \mathrm{~Hz}, 2 \mathrm{H}$ ), 3.44 (t, $J=8.0$ $\mathrm{Hz}, 2 \mathrm{H}$ ). Its spectroscopic characteristics are consistent with those of the same compound reported. $^{21}$

Method II. The standard procedure was followed by use of 9 (464 mg, $2.13 \mathrm{mmol}, 1.0$ equiv), the CAN-silica gel reagent ( $1.17 \mathrm{~g}$, containing $235 \mathrm{mg}$ of CAN, $0.428 \mathrm{mmol}, 0.20$ equiv), and toluene $(7.0 \mathrm{~mL})$. After the reaction mixture was heated at reflux for $3.0 \mathrm{~h}$, it was worked up and 
the residue was purified by column chromatography (20\% $\mathrm{MeOH}$ in EtOAc as eluant) to afford 10 (232 mg, $1.98 \mathrm{mmol}$ ) in 93\% yield.

$N$-Hydroxyphthalimide (12). Method I. The standard procedure was followed by use of $N$ (tert-butoxycarbonyloxy)phthalimide (11, $486 \mathrm{mg}, 1.85 \mathrm{mmol}, 1.0$ equiv), CAN (203 mg, $0.370 \mathrm{mmol}, 0.20$ equiv), and $\mathrm{MeCN}(10 \mathrm{~mL})$. After the reaction mixture was heated at reflux for $1.0 \mathrm{~h}$, it was worked up and the residue was purified by column chromatography (EtOAc as eluant) to afford 12 (298 mg, $1.82 \mathrm{mmol}$ ) in 99\% yield: mp 231-233 ${ }^{\circ} \mathrm{C}$ (dec.). Its physical properties and spectroscopic characteristics are consistent with those of an authentic sample. ${ }^{20}$

Method II. The standard procedure was followed by use of 11 (390 mg, 1.48 mmol, 1.0 equiv), the CAN-silica gel reagent (815 mg, containing $163 \mathrm{mg}$ of CAN, $0.297 \mathrm{mmol}, 0.20$ equiv), and toluene $(7.0 \mathrm{~mL})$. After the reaction mixture was heated at reflux for $0.20 \mathrm{~h}$, it was worked up and the residue was purified by column chromatography (EtOAc as eluant) to afford 12 (239 mg, $1.46 \mathrm{mmol}$ ) in $99 \%$ yield.

4,6-Dimethyl-2-mercaptopyrimidine (14). Method I. The standard procedure was followed by use of tert-butyl $S$-(4,6-dimethylpyrimidin-2-yl)thiolcarbonate (13, $422 \mathrm{mg}, 1.76 \mathrm{mmol}, 1.0$ equiv), CAN (193 mg, $0.350 \mathrm{mmol}, 0.20$ equiv), and MeCN (10 mL). After the reaction mixture was heated at reflux for $0.20 \mathrm{~h}$, it was worked up and the residue was purified by column chromatography (EtOAc as eluant) to afford 14 (236 mg, $1.68 \mathrm{mmol}$ ) in 96\% yield: mp 212$214{ }^{\circ} \mathrm{C}$ (dec.). Its physical properties and spectroscopic characteristics are consistent with those of an authentic sample. ${ }^{20}$

Method II. The standard procedure was followed by use of 13 (350 mg, $1.46 \mathrm{mmol}, 1.0$ equiv), the CAN-silica gel reagent (802 mg, containing $160 \mathrm{mg}$ of CAN, $0.290 \mathrm{mmol}, 0.20$ equiv), and toluene $(7.0 \mathrm{~mL})$. After the reaction mixture was heated at reflux for $0.010 \mathrm{~h}$, it was worked up and the residue was purified by column chromatography (EtOAc as eluant) to afford 14 (201 mg, $1.43 \mathrm{mmol}$ ) in $98 \%$ yield.

Benzoic Acid (16). Method I. The standard procedure was followed by use of tert-butyl benzoate (15, $540 \mathrm{mg}, 3.03 \mathrm{mmol}, 1.0$ equiv), CAN (332 mg, $0.605 \mathrm{mmol}, 0.20$ equiv), and MeCN (10 mL). After the reaction mixture was heated at reflux for $5.0 \mathrm{~h}$, it was worked up and the residue was purified by column chromatography ( $\mathrm{Et}_{2} \mathrm{O}$ as eluant) to afford 16 (362 mg, $2.96 \mathrm{mmol}$ ) in $98 \%$ yield: $\mathrm{mp} 120-122{ }^{\circ} \mathrm{C}$. Its physical properties and spectroscopic characteristics are consistent with those of an authentic sample. ${ }^{20}$

Method II. The standard procedure was followed by use of 15 (476 mg, $2.67 \mathrm{mmol}, 1.0$ equiv), the CAN-silica gel reagent (1.47 g, containing $294 \mathrm{mg}$ of CAN, $0.536 \mathrm{mmol}, 0.20$ equiv), and toluene $(7.0 \mathrm{~mL})$. After the reaction mixture was heated at reflux for $0.20 \mathrm{~h}$, it was worked up and the residue was purified by column chromatography ( $\mathrm{Et}_{2} \mathrm{O}$ as eluant) to afford 16 (310 mg, $2.54 \mathrm{mmol}$ ) in 95\% yield.

\section{Acknowledgments}

For financial support, we thank Ministry of Education of Republic of China. 


\section{References}

1. Wünsch, E. In Methoden der Org Chem, Houben-Weil, Vol. 15/1; Wünsch, E., Ed.; Thieme:Stuttgart, 1974; pp 46-308.

2. Schnabel, E.; Klostermeyer, H.; Berndt, H. Liebigs Ann. Chem. 1971, 749, 90.

3. Stahl, G. L.; Walter, R.; Smith, C. W. J. Org. Chem. 1978, 43, 2285.

4. Yamashiro, D.; Blake, J.; Li, C. H. J. Am. Chem. Soc. 1972, 94, 2855.

5. Houghton, R. A.; Beckman, A.; Ostresh, J. M. Int. J. Pept. Protein Res. 1986, 27, 653.

6. Kocienski, P. J. Protecting Groups; Georg Thieme Verlag Stuttgart: New York, 1994; pp 192-193 and references cited therein.

7. Schmidt, U.; Utz, R.; Lieberknecht, A.; Griesser, H.; Potzolli, B.; Bahr, J.; Wagner, K.; Fischer, P. Synthesis 1987, 236.

8. Vorbrüggen, H.; Krolikiewicz, K. Angew. Chem. 1975, 87, 877; Angew. Chem., Int. Ed. 1975, 14, 818.

9. Hamada, Y.; Shioiri, T. J. Org. Chem. 1986, 51, 5489.

10. Molander, G. A. Chem. Rev. 1992, 92, 29.

11. (a) Hwu, J. R.; Jain, M. L.; Tsay, S.-C.; Hakimelahi, G. H. J. Chem. Soc., Chem. Commun. 1996, 545. (b) Hwu, J. R.; Jain, M. L.; Tsay, S.-C.; Hakimelahi, G. H. Tetrahedron Lett. 1996, 37, 2035. (c) Hwu, J. R.; Jain, M. L.; Tsai, F.-Y.; Tsay, S.-C.; Balakumar, A.; Hakimelahi, G. H. J. Org. Chem. 2000, 65, 5077.

12. For recent reviews; see (a) Steel, P. G. J. Chem. Soc., Perkin Trans. 1 2001, 2727. (b) Hwu, J.R.; King, K. Y. Curr. Sci. 2001, 81, 1043. (c) Ho, T.-L. In Encyclopedia of Reagents for Organic Synthesis; Paquette, L. A. Ed.; John Wiley \& Sons: New York, 1995; Vol. 2, pp 1025-1029.

13. Diddams, P. In Solid Supports and Catalysts in Organic Synthesis; Smith, K., Ed.; Ellis Horwood: New York, 1992; Ch. 1.

14. Butters, M. In Solid Supports and Catalysts in Organic Synthesis; Smith, K., Ed.; Ellis Horwood: New York, 1992; Ch. 3.

15. Keinan, E.; Mazur, Y. J. Org. Chem. 1978, 43, 1020.

16. Hudlicky, M. J. Org. Chem. 1974, 39, 3460.

17. Taylor, E. C.; Chiang, C. S.; McKillop, A.; White, J. F. J. Am. Chem. Soc. 1976, 98, 6750.

18. Ho, T. L. In Organic Syntheses by Oxidation with Metal Compounds; Mijs, W. J.; de Jonge, C. R. H. I., Eds; Plenum Press: New York, 1986; pp 569-631.

19. Janzen, E. G.; Wilcox, A. L.; Manoharan, V. J. Org. Chem. 1993, 58, 3597 and references cited therein.

20. Compounds are available from Aldrich or Sigma Chemical Co.

21. Harder, U.; Pfeil, E.; Zenner, K.-F. Chem. Ber. 1964, 97, 510. 